BRE 10312

\title{
Transduction Physiology of Olfactory Receptor Cilia
}

\author{
GLORIA D. ADAMEK ${ }^{1}$, ROBERT C. GESTELAND ${ }^{1}$, ROBERT G. MAIR ${ }^{1, *}$ and BRUCE OAKLEY ${ }^{2}$ \\ ${ }^{1}$ Graduate Program in Neuroscience and Department of Neurobiology and Physiology, Northwestern University, Evanston, IL 60201 \\ and ${ }^{2}$ Division of Biological Sciences, University of Michigan, Ann Arbor, MI 48109 (U.S.A.)
}

(Accepted February 21st, 1984)

Key words: electro-olfactogram — olfactory — cilia — regeneration — receptor - development

\begin{abstract}
Electro-olfactograms (EOGs) evoked by 8 odorants from frog olfactory epithelia during ciliary regrowth and during epithelial regeneration were analyzed. During ciliary regrowth following detergent-induced ciliary removal, EOG amplitudes initially increase proportionately with ciliary length. EOGs reach maximal amplitudes after 2 days of growth, when cilia are $40 \mu \mathrm{m}$ long. Therefore olfactory transduction sites are located primarily on cilia rather than on the dendrite terminal and most of the receptor current enters through the proximal portion of the cilium.

Zinc sulfate lavage of the nasal cavity causes selective necrosis of the receptor epithelium. During epithelial regeneration, EOGs increase linearly with time from 13 days after zinc lavage, the time of first cilium emergence, through 30 days. The rate of increase is different for different odorants. At 30 days and within a period of a few days, EOG amplitudes increase abruptly, then asymptote. Thus the development of receptors for different substances occurs at different rates and occurs in two steps. The transition between the two developmental states is coincident with arrival of receptor axon terminals at the central nervous system and with the immobilization of the ciliary contractile apparatus.

Since there is continual generation of new receptor neurons throughout life, EOGs recorded in a normal nose reflect a complex combination of the differing receptor processes of cells of differing developmental stages.
\end{abstract}

\section{INTRODUCTION}

The site of odorant transduction in the olfactory epithelium is not known. The monophasic, negative component of the electro-olfactogram (EOG) is generally considered to result from depolarizing receptor currents flowing through the extracellular space. The cells which give rise to this current are the olfactory neurons $36,39,40$. The locations of the current sources which constitute the EOG of the olfactory epithelium are currently a matter for speculation.

Ottoson ${ }^{30}$, on the basis of morphological and electrophysiological evidence, suggested that the sites of odorant-receptor neuron interaction and the sites of generation of the EOG response were the olfactory cilia, which are borne by receptor neurons. The purpose of the first part of our study was to determine if this is so. In the mature frog nose under the light mi- croscope, 3 ciliary types are distinguishable on the basis of motility differences ${ }^{32,34}$. In some regions there are cilia about $10 \mu \mathrm{m}$ long which beat very rapidly in a metachronally synchronized pattern. These are the cilia of the cells of the respiratory epithelium which is not part of the chemosensory apparatus. Different ciliary types are located in other regions. These are found on olfactory receptor neurons. In some patches there are $10-50 \mu \mathrm{m}$ long, motile cilia. These cilia move independently of each other rather than metachronally, and less rapidly than cilia of the respiratory epithelium. In other patches immotile cilia $20-200 \mu \mathrm{m}$ long are found. In some places these two types are intermingled.

Previous studies of the effect of ciliary removal on the EOG produced conflicting results. Mechanical treatment of the olfactory epithelium of the box turtle removed mucus but left short, motile olfactory ci-

\footnotetext{
* Present address: V.A. Hospital, Providence, RI, U.S.A.

Correspondence: R. C. Gesteland, Graduate Program in Neuroscience and Department of Neurobiology and Physiology, Northwestern University, Evanston, IL 60201, U.S.A.
} 
lia ${ }^{35}$. The EOG response was diminished but the neural response did not change much. Tucker ${ }^{41}$ removed olfactory cilia chemically. $\mathrm{He}$ also found that the EOG was impaired more than the neural response and concluded that the cilia were not necessary for receptor neuron function. Neither of these studies examined the whole epithelium to determine the extent of ciliary removal. In the frog, the two types of olfactory cilia can be removed uniformly using a detergent rinse ${ }^{4,23}$. The cilia are cleaved near their bases and then regrow. In the first part of our investigation EOGs were measured in this preparation at various times after detergent treatment to reveal how ciliary regrowth is related to the electrophysiological response.

The second part of our investigation was designed to study how EOGs elicited from a population of cells consisting of newly differentiated receptor neurons differed from those recorded in the mature nose with its heterogeneous population of receptor neurons of differing developmental ages. In vertebrates, new receptor neurons are constantly generated from stem cells in mature tissue 17,26,27. Electrophysiological measurements in the normal nose, therefore, reflect activity of cells in a variety of developmental states. After intranasal irrigation with appropriate concentrations of $\mathrm{ZnSO}_{4}$, the olfactory epithelium degenerates, sloughs, and then regenerates 25.29 .33 .37 .38 . The respiratory epithelium remains. Return of odorantmediated behavior parallels regeneration 2,18 . Efficacy of this coagulation necrosis and the subsequent recovery has recently been reviewed 1.7 . In the frog, use of appropriate $\mathrm{ZnSO}_{4}$ concentrations and application procedures results in uniform ablation followed by an orderly regeneration within 3 months. The denuded olfactory area is first repopulated by respiratory epithelial cells. These cells bear highly motile cilia less than $10 \mu \mathrm{m}$ long. Their movements are metachronally synchronized. Subsequently, patches of olfactory cells form and replace respiratory cells. As these patches mature, new islands of olfactory cells add to the population. Ultimately, the original contiguous receptor area is replaced. The developmental states of these cells are indentifiable by observation of ciliary length and motility ${ }^{23}$. Up to 4 weeks after treatment, only short, motile cilia are seen on olfactory receptor neurons. After this time, longer, immotile cilia appear. EOGs were recorded from noses treated with $\mathrm{ZnSO}_{4}$. EOGs recorded before the time at which immotile olfactory cilia are seen reflected activity of newly differentiated receptor neurons.

Preliminary reports on return of the EOG following $\mathrm{ZnSO}_{4}$ and Triton X-100 treatment have been presented 6,14

\section{MATERIALS AND METHODS}

Adult northern Rana pipiens (Nasco, Inc., Fort Atkinson, WI) were pithed both anteriorly and posteriorly, pinned to a cork board, and covered with a wet cotton gauze. To prevent movement, $0.45 \mathrm{mg}$ of tubocurarine chloride (Squibb, New York) was injected under the skin of the back.

\section{Surgery and microscopic observation}

At the beginning of each experiment the dorsal olfactory epithelium was surgically removed from both the treated and untreated sides. The tissue was folded and placed in a pool of Woods Hole amphibian Ringer on a slide, held in place with a coverslip and examined by viewing the cilia along the folded edge with Nomarski differential interference contrast (DIC) optics. This light microscopic (LM) observation provided an estimate of the stage of tissue regeneration. After the recording session, tissue from the ventral olfactory epithelium where the EOGs were recorded was removed and examined with the scanning electron microscope (SEM) to verify the assignment of developmental state determined by DIC observations. Mair et al. ${ }^{23}$ described in detail the sequence of regrowth and regeneration following the two chemical treatments. Their determinations of ciliary growth rates are compared with EOG amplitude changes here. The same groups of frogs were used for the Mair et al.23 SEM micrographs and for EOG measurements reported here. Some frog olfactory epithelia are common to both studies.

\section{Physiological recordings}

A chlorided silver plate covered with cotton gauze moistened with Woods Hole amphibian Ringer in the frog's mouth served as a ground electrode. Glass pipettes with tip diameters of $20-50 \mu \mathrm{m}$ and filled with $0.6 \%$ saline and $1 \%$ gelatin solution were used to measure EOGs ${ }^{12}$. EOGs were recorded from the top of the median eminence on the ventral surface of the 
olfactory cavity. This area, which is readily identifiable from frog to frog, has the highest density of receptor neurons and produces consistently larger EOGs than other locations in the nasal cavity 30 .

Changes in relative EOG amplitudes during ciliary regrowth and during epithelial regeneration are central issues in this study. Since the EOG is the voltage resulting from receptor current flowing through the bulk epithelial resistance, an amplitude change could be due to a current change, a resistivity change or both. Therefore epithelial bulk resistance was measured in each experimental situation. Comparative resistances were determined by measuring the noise voltage amplitude from a low-noise metal extracellular electrode plated with platinum black ${ }^{10}$. The tip diameter of the electrode was 5-7 $\mu \mathrm{m}$. Noise bandwidth was $30 \mathrm{~Hz}-15 \mathrm{kHz}$. The electrode noise was generally $20 \mu \mathrm{V}$ peak-to-peak at the surface of the mucus and in $0.6 \% \mathrm{NaCl}$. This is equal to the noise seen when a $75 \mathrm{k} \Omega$ resistor replaces the electrode and Ringers. Since equivalent noise resistance is proportional to the square of the noise voltage amplitude, this method proves to be a sensitive one. Resistance differences as small as $20 \%$ were easily detected, more than adequate sensitivity in view of the large EOG amplitude changes which occurred. Metal electrodes were used because their resistances are small compared to the resistances of tissue, assuring that the noise voltages measured were due to tissue rather than electrode thermal noise.

Resistance measurements were made in the mucus layer, in the dendrite region close to the tight junctions which connect the apices of the receptor dendrites and supporting cells, and deeper where receptor somata lie. Resistances were determined immediately after $0.025 \%$ Triton lavage, and 3,8 and $12 \mathrm{~h}$ after lavage, immediately after $0.1 \mathrm{M} \mathrm{ZnSO} 4$ lavage, and $4,10,16,21$ and 39 days after lavage, and in untreated control animals.

\section{Stimuli and stimulus presentation}

We chose stimulus substances with a wide range of water solubilities. The 8 odorous chemicals we used were methyl amyl ketone, pyridine, butanol, amyl acetate, octanol, limonene, methyl acetate and anisole. All stimuli were presented for $2 \mathrm{~s}$ with a 2-min interstimulus interval. There was no decrement in EOG amplitude with stimulus repetition in control animals for interstimulus intervals longer than $1 \mathrm{~min}$. Clean, moisture-saturated air flowed continuously over the exposed epithelium at a rate of $4 \mathrm{ml} / \mathrm{s}$. During stimulus presentation, a portion of this stream was diverted to the selected stimulus vial. The headspace vapor displaced from the vial was then added back into the carrier stream so that the saturated vapor was diluted without change in the total gas flow rate. In preliminary experiments we determined that all 8 stimulus substances presented at concentrations of $3.3 \%$ of saturated vapor produced adequate sensitivity without saturating the receptors. All EOG amplitudes reported here were obtained with stimuli at this concentration.

\section{Common procedures}

Perfusion techniques used in this study duplicated those used in the companion study 23 . The two nasal cavities in frogs are separated by a septum. In order to obtain control and experimental EOG values from the same animal, the solutions were administered so that they would not reach the contralateral side. Solution effects were consistent only when there was sufficient mechanical agitation in application. About $2.5 \mathrm{ml}$ was squirted every $15 \mathrm{~s}$ at one internal naris through a blunted 16-gauge needle. The tip was about $1 \mathrm{~mm}$ away from the naris. Approximately one-third of the squirted fluid passed through the cavity and out the external naris.

\section{Deciliation procedure}

Cilia were removed by perfusing one olfactory cavity of each frog with a solution of Triton X-100 in Woods Hole amphibian Ringer followed by Ringer rinse. (Ionic composition of Woods Hole amphibian Ringer is $114 \mathrm{mM}$ sodium, $1.9 \mathrm{mM}$ potassium, $1.09 \mathrm{mM}$ calcium, $115 \mathrm{mM}$ chloride, $2.4 \mathrm{mM}$ bicarbonate and $0.87 \mathrm{mM}$ phosphate.) A total of $50 \mathrm{ml}$ of the detergent solution was used during a 5-min period. Immediately after the detergent infusion, $20 \mathrm{ml}$ of Ringer solution was applied in the same manner for a duration of $2 \mathrm{~min}$. Three concentrations of detergent were used: $0.05 \%(\mathrm{v} / \mathrm{v}), 0.025 \%$ and $0.013 \%$. The $0.05 \%$ and $0.025 \%$ solutions resulted in complete removal of olfactory cilia. The $0.013 \%$ solution did not result in ciliary removal. EOGs were measured first in a group of frogs $(n=9)$ treated unilaterally with $0.05 \%$ Triton. Subsequently, EOGs 
were recorded in a second group of frogs $(n=21)$ which were unilaterally subjected to $0.025 \%$ Triton. Experiments occurred immediately after treatment, at $6 \mathrm{~h}$ and $18 \mathrm{~h}$, and at 1,2, 3 and 4 days after treatment. For the $0.05 \%$ Triton series, two animals were used for electrophysiological studies for each of the data points plotted in Fig. 1 except for day 3 when one animal was used. For the $0.025 \%$ series, two animals were recorded at $6 \mathrm{~h}, 5$ at $18 \mathrm{~h}, 4$ each at 1,2 and 4 days and 1 at 3 days after treatment. Fig. $3 e$ in ref. 23 is from these epithelia which were examined with SEM. The presence of cilia longer than $100 \mu \mathrm{m}$ before day 4 indicated incomplete deciliation. Data from these animals were excluded. Control EOG values were obtained from epithelia on the untreated sides of experimental animals. Percent recovery of EOG amplitude was plotted as a function of time after treatment. It was determined by dividing the response amplitude of the treated side by the amplitude recorded from the control side.

\section{Ablation procedure}

Degeneration of the olfactory epithelium was induced by perfusion of the nasal cavity with $\mathrm{ZnSO}_{4}$. Twenty $\mathrm{ml}$ of $0.1 \mathrm{M} \mathrm{ZnSO}_{4}$ in distilled water was squirted at the internal naris for a duration of $2 \mathrm{~min}$. EOGs were recorded from one or two frogs at 5, 13, $19,23,25,29,34,41,48$ and 55 days after treatment; a total of 13 frogs were used. Figs. $5 \mathrm{a}$ and $6 \mathrm{c}-\mathrm{f}$ in Mair et al. ${ }^{23}$ came from this group of epithelia viewed with SEM. Recovery was determined in the same manner as after the detergent treatment, but control values were obtained from untreated animals because of the systemic effect of $\mathrm{ZnSO}_{4}$ on the contralateral side. EOG amplitudes recorded from the unperfused side during the first 4 weeks following treatment were less than those from the noses of normal frogs or from the control side of frogs treated with Triton. When viewed with DIC optics, tissue from the control side showed degeneration. It is likely that the $\mathrm{ZnSO}_{4}$ reached the untreated side through the circulatory system. However, no other obvious systemic effect of the $\mathrm{ZnSO}_{4}$ treatment was observed. Epithelia from another group of frogs $(n=18)$ recovering from $\mathrm{ZnSO}_{4}$ treatment were immersed in Bouin's fixative and $7-\mu \mathrm{m}$ thick transverse sections of the fixed tissue were cut in paraffin and stained with hematoxylin and eosin.

\section{Statistical analysis}

We wanted to know if the differences due to odor could be accounted for by physicochemical properties of the odorants rather than by highly stimulusspecific receptor mechanisms. We chose to investigate 6 physical parameters (concentration in air (MOL), molecular length (LEN), refractive index function (RIF), molar volume (MV), molar refraction (MR) and log partition coefficient (LP) as defined in Table I). Column B in Table I shows the molarities of head space vapors over the pure chemicals calculated from the ideal gas law. We do not have accurate information on tissue solubilities of these substances and therefore do not know the concentrations of the stimuli at the receptor surface. Columns $\mathrm{C}-\mathrm{G}$ list values for 5 physicochemical variables which appear to be most useful in classifying odorants $^{8}$. These latter 5 parameters are themselves related to parameters deemed important by others ${ }^{9}, 22$.

An analysis of covariance of EOG responses by the 6 physical stimulus parameters, time and odor was performed. EOG responses recorded during the first day following Triton treatment and during the first 4 weeks following $\mathrm{ZnSO}_{4}$ treatment were used in the analysis.

In order to perform the analysis of variance, it was necessary to have a normal distribution of the responses or find some transform which yielded a normal distribution. The responses did not have a normal distribution. Since the responses of many sensory systems are related to the logarithm of the stimulus intensity and since Ottoson ${ }^{30}$ showed such a logarithmic relationship for butanol in the normal frog nose, we tried a logarithmic transform of the data. This yielded a normal distribution. This is reasonable since during the early period of this experiment the pool of receptor cells is rapidly expanding and exponential growth of a population is the same as linear growth of the logarithm of the population.

\section{RESULTS}

\section{Recovery after deciliation}

DIC and SEM measurements showed that $0.05 \%$ Triton lavage left immotile ciliary stumps $4-8 \mu \mathrm{m}$ long. There appeared to be systemic effects, however. EOGs from the untreated side of the nose were 
TABLE I

Concentrations and physical properties of stimulus substances

Column A, name by rank order of slopes in Fig. 2 . MOL, molarity in air $\times 10^{-4}$. Calculated from the ideal gas law, $\mathrm{T}=20^{\circ} \mathrm{C}$, vapor pressure values obtained or extrapolated from R. C. Weast (Ed.), Handbook of Chemistry and Physics, 49th edn., Chemical Rubber (CRC), Ohio, 1969. LEN, length $(\AA)$. Long axis of molecular model ${ }^{9}$ calculated by addition of intramolecular bond lengths obtained from H. Curtis, Biology, 2nd edn. Worth, New York, 1975. RIF, refraction index function. $\left(\mathrm{n}^{2}-1 / \mathrm{n}^{2}+2\right)($ ref. 8$)$; refraction indices $\mathrm{n}_{\mathrm{D}}^{20}$ obtained from CRC Handbook. MV, molar volume (ml). Molecular weight/density ; values obtained from CRC Handbook. MR, molar refraction (= MV $\times$ RIF) (ref. 8). LP, log partition coefficient. Octanol/water partition coefficient values from the review by A. Leo, C. Hansch and D. Elkins, Partition coefficients and their uses, Chem. Rev., 71 (1971) 525-616, or calculated by the method of G. G. Nys and R. F. Rekker, The concept of hydrophobic fragmental constants ( $F$-values). II. Extension of its applicability to the calculation of lipophilicities of aromatic and heteroaromatic structures, Europ. J. Med. Chem., 9 (1974) 361-375.

\begin{tabular}{|c|c|c|c|c|c|c|}
\hline$A$ & $B$ & $C$ & $D$ & $E$ & $F$ & $G$ \\
\hline Name & $M O L$ & $L E N$ & $R I F$ & $M V$ & $M R$ & $L P$ \\
\hline Amyl acetate & 2.35 & 11.0 & 0.242 & 148.6 & 85.9 & 2.12 \\
\hline Methyl acetate & 94.04 & 6.5 & 0.219 & 79.8 & 17.47 & 0.18 \\
\hline Anisole (Methoxybenezene*) & 1.59 & 9.5 & 0.302 & 108.6 & 32.79 & 2.11 \\
\hline (DL)Limonene & 0.94 & 11.0 & 0.279 & 162.1 & 45.3 & 4.40 \\
\hline Butanol (1-Butanol*) & 3.17 & 8.2 & 0.242 & 91.5 & 22.14 & 0.83 \\
\hline Pyridine (Azine*) & 8.82 & 5.0 & 0.298 & 80.7 & 24.04 & 0.65 \\
\hline Octanol (1-Octanol*) & 0.06 & 14.3 & 0.258 & 157.4 & 40.60 & 3.15 \\
\hline Methyl amyl ketone (2-Heptanone*) & 0.70 & 11.4 & 0.246 & 139.3 & 34.26 & 1.82 \\
\hline
\end{tabular}

* Name approved by the International Union of Chemists.

often smaller than those in control animals. EOG recovery with ciliary regrowth was not complete and some animals died. The EOG in response to all odorants was first measurable $18 \mathrm{~h}$ following treatment (Fig. 1). EOG waveshapes appeared no different from those recorded in a normal nose, but amplitudes were much smaller. The mean EOG amplitude for all 8 odorants at $18 \mathrm{~h}$ was $6 \%$ of the control amplitude. Butanol consistently elicited the smallest amplitude EOGs at all times, while amyl acetate evoked the largest. In one frog at $18 \mathrm{~h}$, the butanol-evoked EOG amplitude was $3 \%$ of control values, or $0.04 \mathrm{mV}$, while amyl acetate evoked a $6 \%$ or $0.4 \mathrm{mV}$ response. The average ciliary length at $18 \mathrm{~h}$ was $20 \mu \mathrm{m}$. As the cilia lengthened, the EOG amplitude increased. Twenty four $h$ after treatment EOG amplitudes were $33 \%$ of the control values (Fig. 1). By $48 \mathrm{~h}$ after treatment, the EOG response had attained $60 \%$ of the control value and remained at that level for the next 2 days, although some cilia continued to grow at a rate of $20 \mu \mathrm{m}$ per day.

Treatment with $0.025 \%$ Triton resulted in ciliary stumps $6-10 \mu \mathrm{m}$ long. DIC examination of the epithelium immediately after treatment showed that the treated side looked like the control side except for the lack of cilia. In most animals all of the cilia were cleaved. However the stumps were longer than with

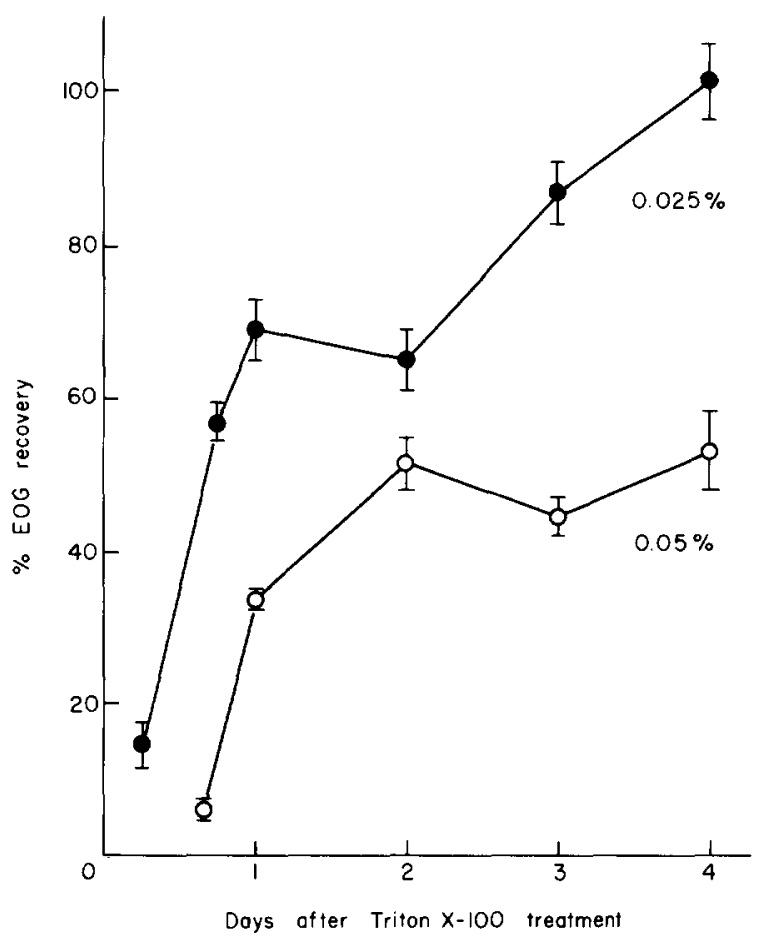

Fig. 1. EOG recovery after deciliation with Triton X-100. Each point is the mean of the sum of the normalized EOG responses to all 8 odorants for all animals at the specified time. The error bars represent the standard error. When more than one series of measurements were performed on a frog, then the second series was generally used. 
the $0.05 \%$ treatment and EOG amplitudes immediately after treatment were not quite zero. EOGs from the untreated side of the nose were indistinguishable from those in control animals. The regrowth rate was the same as after $0.05 \%$ Triton treatment. At $6 \mathrm{~h}$ after treatment, the mean EOG amplitude was $11 \%$ of the control value (Fig. 1). The EOG amplitude increased in a linear manner during the subsequent $18 \mathrm{~h}$. In frogs studied $24 \mathrm{~h}$ after treatment, some cilia were about $30 \mu \mathrm{m}$ long and the EOG amplitude averaged $67 \%$ of the control value. On the second day, the averaged EOG amplitude was $65 \%$ and on the third day it was $87 \%$ of control values. By the fourth day, EOG amplitudes were the same for treated and untreated epithelia. Some cilia continued to lengthen during the next few days and attained their final lengths 8 days or more after treatment.

Resistance of the tissue measured as the square of peak-to-peak voltage noise amplitude at any epithelial depth in Triton-treated animals was the same as that in control animals at $1 \mathrm{~h}$ after treatment and thereafter. When the electrode touched mucus, it looked like a $75 \mathrm{k} \Omega$ resistance. There was a sharp discontinuity at a depth corresponding to the level of the tight junctions between receptor cell and supporting cell apices. The resistance increased by a factor of 4 . Deeper in the epithelium, in the region populated by receptor somata, the resistance was typically 10 times that seen in mucus.

EOG responses recovered rapidly during the first $24 \mathrm{~h}$ after treatment. EOG responses measured during this period after treatment showed a normal distribution. The results of the analysis of covariance of these EOG responses by stimulus physical parameters, time and odor showed that the main effect of the physical parameters showed a trend to significance $F(6,78)=2.141$, with $P<0.05$. The main effect due to time was significant $F(2,78)=52.298, P<0.01$, and the main effect of odor name was not significant.

\section{Recovery after $\mathrm{ZnSO}_{4}$ treatment}

Physiological results. The EOG for all odorants tested was first distinguishable from low frequency noise 13 days after treatment (Fig. 2), the time at which olfactory cilia were first seen. From the 13th through 29th days following treatment, relative EOG amplitudes appeared to increase linearly (Fig. 2).
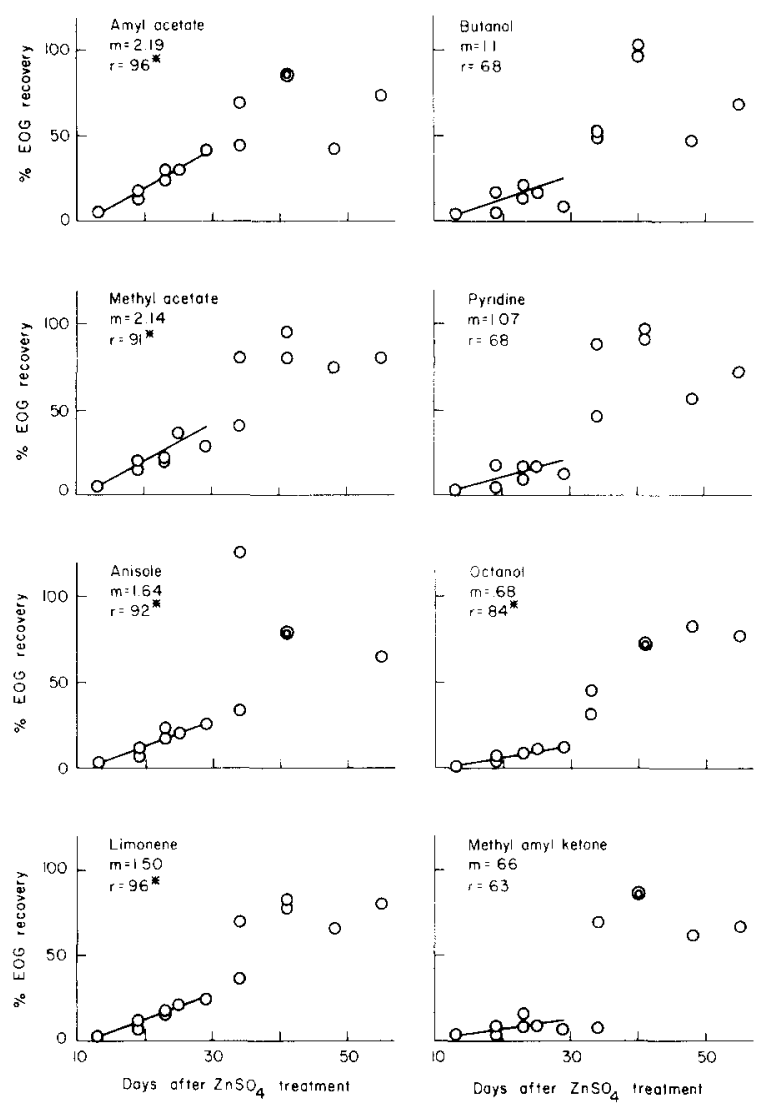

Fig. 2. EOG recovery for different stimulus substances during regeneration following $\mathrm{ZnSO}_{4}$ treatment. $\mathrm{m}$, slope of the best fit' line; $r$, regression coefficient; ${ }^{*}$ represents a significance level of $P<0.05$. As expected, plotting the log of responses yields a set of non-overlapping parallel lines for values through the 29 th day.

Regression analysis was used to determine the slopes of the 'best fit' lines and to determine how well EOG amplitudes could be predicted by time after treatment. The slopes, or rates of return of EOG amplitude, differed among odorants. There was a significant $(P<0.01)$ correlation between percent of control EOG magnitude and time after treatment for 5 of the 8 odorants. On the 28 th day following zinc treatment, the maximum amplitudes ranged from $10 \%$ of control values for methyl amyl ketone to $40 \%$ for amyl acetate.

Epithelial resistance in the early days after $\mathrm{ZnSO}_{4}$ lavage was between 75 and $150 \mathrm{k} \Omega$ and showed no sharp discontinuities as the electrode was advanced through the tissue. From 13 days after $\mathrm{ZnSO}_{4}$ treatment onward, resistances seen by the extracellular electrode were like those in control animals. The resistance in mucus was about $75 \mathrm{k} \Omega$. It increased by a 
factor of 4 when the electrode entered the receptor dendrite region and by a factor of 10 in the receptor somata region. The resistance of the basement membrane boundary in $\mathrm{ZnSO}_{4}$ treated epithelia after 13 days was the same as that of untreated animals.

EOG responses measured during the first 29 days after treatment showed a skewed distribution. Transforming the data by taking the log of the response (lnresp) yielded a normal distribution of responses. All further analyses used lnresp as the dependent variable. Analysis of variance of Inresp by time and odor showed that the main effects of time $F(4,16)=$ 19.403, $P<0.01$ and odor $F(7,16)=4.661$, $P<0.01$ were significant, but the time-by-odor interaction was not significant. To determine the effect of the 6 chosen physical parameters of the odorants on Inresp, an analysis of covariance of Inresp by time with physical parameter as the covariate was performed. Results of this analysis showed that the main effects of the parameters $F(6,21)=10.011, P<0.01$ and time $F(4,21)=18.113, P<0.01$ were significant but the interaction was not significant. To determine whether odor had an effect on EOG responses beyond that accounted for by physical parameters and time, analysis of covariance of lnresp as a function of the parameters, time and odor was performed. Results of this analysis showed that the effects of the physical parameters $F(6,44)=9.726, P<0.01$ and

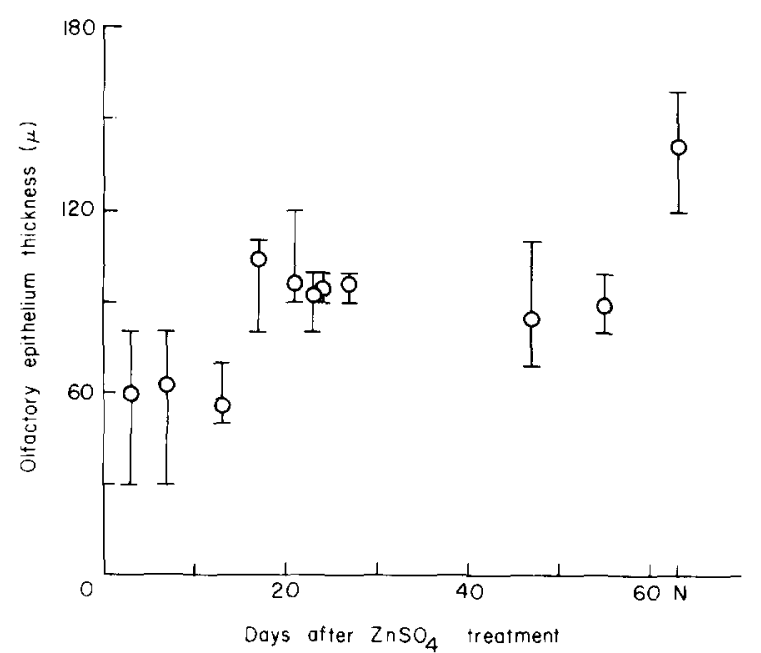

Fig. 3. Histological changes following $\mathrm{ZnSO}_{4}$ treatment and control. Mean epithelial height not corrected for shrinkage. The error bars indicate the range of thicknesses observed. Ranges are based on a minimum of 5 observations per crosssection of olfactory epithelium on 17 frogs. time $F(4,44)=33.836, P<0.01$ were significant and the effect due to odor was not significant. Additionally, 4 of the 6 physical parameters, MOL, MR, MV and LP, accounted for most of the variance of the physical parameters $(P<0.01)$.

Days 27-41 following zinc sulfate treatment constitute a transition period in EOG development. EOG amplitudes depart from their linear increase with time and rapidly attain assymptotic levels of $80 \%$ of control values (Fig. 2). Animal-to-animal variation can be large during this period. The change in slope for the recovery function is more variable for methyl amyl ketone, anisole, pyridine and methyl acetate than it is for the other stimulus substances. The change in slope is most abrupt for those substances with lowest increase rates during the preceding 14 days. These include methyl amyl ketone, octanol, butanol and pyridine. The rank order of the slopes before day 29 is unrelated to the rank order of the EOG amplitudes finally attained at the end of the transition period.

Tissue resistances in these animals were the same as those in control animals.

Morphological observations. Following lavage of the olfactory cavity with $\mathrm{ZnSO}_{4}$, receptor neurons, supporting cells, and basal cells sloughed from the olfactory area, but Bowman's glands remained. The region was repopulated by respiratory epithelial cells. Cellular proliferation occurred slowly through the 13th day. After the second week, there was an increase in cell number and the tissue began to regain its orderly structure. By the 55th day the olfactory epithelium resembled that of the control. Measurements of epithelial thickness at various times after treatment showed that regeneration occurred in two stages (Fig. 3). The first stage terminated after 2 weeks when the epithelium was $60 \mu \mathrm{m}$ thick. After this time, thickness increase rate slowed. The tissue was $100 \mu \mathrm{m}$ thick on the 55th day after treatment. Thickness of the control epithelium was $140 \mu \mathrm{m}$.

\section{DISCUSSION}

The results reported here show for the first time that: (a) the vast majority of odor receptors are located on receptor cell cilia; (b) the proximal portion of the ciliary membrane contributes more to the total receptor current than does the distal portion; (c) dur- 
ing receptor cell development, receptors for different odorous substances develop at different rates; and (d) there is a transition in physiological response to odors which co-occurs with transition of the receptor neuron cilia to their mature immotile state. The validity of the results which locate receptors on the ciliary membrane is particularly convincing because we found parallel effects using two very different experimental procedures, and because we show that reduced EOG amplitudes were not caused by experimentally-induced changes in epithelial resistivity.

\section{EOGs and ciliary lengths}

When cilia are removed from receptor cells, they are rapidly replaced. Ciliary lengths increase from a few $\mu \mathrm{m}$ to $40 \mu \mathrm{m}$ in 2 days. When the olfactory epithelium is removed, it is replaced. Following a reorganization period, new receptor neurons develop. When their dendrites grow to reach the mucosal surface, cilia begin their growth processes, and odorevoked receptor currents can first be detected. Ciliary elongation proceeds slowly during this phase of receptor generation, requiring about 18 days for $40 \mu \mathrm{m}$ of extension.

In the case of ciliary removal, cellular processes mandate maximal ciliary regrowth. The growth rate we found matches that found in the frog following Triton-induced deciliation ${ }^{4}$ and in the landstage newt following deciliation induced by hypotonic shock ${ }^{24}$. In the case of epithelium regeneration, the rate of ciliary regrowth is determined by the developmental state of the cell rather than those processes responding to damage repair. During regeneration ciliary extension is an order of magnitude slower than during ciliary repair. In spite of this, the EOG-length relationship is found to be invariant. For the first $40 \mu \mathrm{m}$ of ciliary extension, the magnitude of odor-evoked receptor currents, as monitored by EOG amplitude, is proportional to ciliary length, i.e. ciliary membrane area. When cilia are shorter than about $4 \mu \mathrm{m}$, no EOG can be recorded. We do not know whether this is because the dendrite terminal knob and that portion of the ciliary membrane close to it contain no odor receptor sites or whether there are sites but that the evoked currents are masked by the noise level of the recording methods.

It can be argued that receptor sites are primarily on dendritic knobs and that the reduction in EOG amplitude following Triton lavage is due to cell membrane or cell-cell junction damage. When Triton is used for deciliation, concentrations are critical. The optimum varies somewhat from animal to animal. Triton $0.013 \%$ had no effect on ciliary length or on EOG amplitude. Triton $0.025 \%$ effectively cleaved cilia with minimal systemic effects. It is possible that Triton at the $0.025 \%$ level caused changes in cellular adhesion not evident histologically but significant enough to cause a low-resistance current path from the mucosal surface to the basement membrane. This would reduce EOG amplitudes independently of any ciliary processes. Measurements of epithelial resistivities following Triton exposure show that this is not the case. Epithelial resistances were like those of control animals within $1 \mathrm{~h}$ after Triton lavage.

Triton can have other effects on cell membranes. The reduced EOG amplitudes soon after treatment could be due to disruption of processes responsible for maintaining ionic gradients or receptor ionophores. We think this did not occur because spontaneous action potential activity in receptor cells following Triton treatment appeared normal. Cells showed a brief period of abnormal spike firing, a return to normal resting firing rates and interval patterns in less than $6 \mathrm{~h}$, and a return of odor-evoked changes in firing rate with further ciliary regrowth (ref. 14 and unpublished observations).

In the zinc sulfate-treated frogs, no Triton was used. Normal regrowth processes regenerated an epithelium with receptor neurons and cell-cell junctions unexposed to any potentially damaging reagents. In these frogs, the same relation between ciliary length and EOG amplitude was found as was found in the Triton experiments.

Extracellularly measured local tissue resistivities 13 days and later after treatment were the same as control animals. The reduced EOG amplitudes during regeneration are not due to tissue short circuits.

The central role of cilia in receptor current generation is confirmed by histological observations following zinc treatment. EOG amplitudes are proportional to mean ciliary length and not simply related to cell density or cell number (deduced from the changes in the total thickness of the regrowing epithelium plotted in Fig. 3). Olfactory cilia are first seen 12-14 days after zinc treatment. EOGs in response to odors first appear at this time. Smith ${ }^{38}$ reported that cellu- 
lar proliferation occurs slowly before this time and becomes more rapid between days 14 and 28 , as we have found (Fig. 3). On the other hand, there is a rapid increase in EOG amplitude between the 29th and 41 st days after zinc treatment which is not related to any change in epithelial thickness (Fig. 2). This acceleration in EOG amplitude increase co-occurs with the transition of motile cilia to immotility ${ }^{23}$. It is possible that the appearance of immotile cilia signals the conversion of the cilium from a propulsive element into a transducing element. Olfactory cells bearing immotile cilia would then resemble the sensory cells of the acoustic, lateral-line and visual systems, all of which bear a modified cilium ${ }^{3}$.

\section{Localization of the EOG current}

The EOG amplitude increases rapidly during the first 2 days of ciliary regrowth, slows during the third day, and remains constant after this time. (Fig. 1). From Mair et al. ${ }^{23}$, we know the following. Ciliary growth rate is constant, averaging $20 \mu \mathrm{m}$ per day. Maximum lengths achieved depend upon the developmental state of the cell from which the cilium grows. Cells which are developmentally younger than 4 weeks have motile cilia which are an average of $20 \mu \mathrm{m}$ long. Cells older than 4 weeks have immotile cilia averaging $40 \mu \mathrm{m}$ in length in the 4 th week, $60 \mu \mathrm{m}$ in the 5th week, and $80 \mu \mathrm{m}$ in the 6 th week. During ciliary regrowth following deciliation, therefore, all cilia grow at the same rate, but those on some cells cease growth at different lengths than those on others. Cilia on the most mature cells reach lengths greater than $160 \mu \mathrm{m}$ in 8 days.

Either most of the current responsible for the EOG is contributed by the proximal portions of the cilia or the number of cells mature enough to grow long cilia is so small a fraction of the total population that their contribution to the EOG is negligible. We think the former more likely. Observations of the living epithelium with light microscopy indicates that long, immotile cilia are not rare. Using Hopkins' method ${ }^{19}$ of scanning along the folded edge of pieces of epithelium we find that long, immotile cilia are encountered as often as are short motile ones. Mair et al. ${ }^{23}$, who examined hundreds of folds, also did not find a predominance of one ciliary type. If the developmental process is linear cells with motile cilia and cells with immotile cilia should be present in approxi- mately equal numbers. (Cell turnover time is 6-8 weeks and the transition from ciliary motility to immotility occurs at the end of 4 weeks.) The failure of the EOG to increase after the third day of ciliary regrowth is therefore probably not due to scarcity of longer cilia.

There is other evidence that transduction occurs primarily on the proximal portions of the cilia. Getchell et al. ${ }^{15}$ found that response latency correlated with diffusion time through most of the mucus layer. Furthermore, the internal resistance of the proximal portion of the cilium is probably lower than the distal portion. The proximal region has a conventional 9 peripheral plus 2 central tubule structure. The distal portion is much reduced, consisting of a few singlet tubules with very little cilia plasma. High internal resistance of the distal portion would be expected to reduce contributions to the receptor current from transduction sites located there. There has been no measurement of the lengths of the two regions. It has been stated that in long frog olfactory cilia, the reduced, distal portions are longer than the $9+2$ proximal portions ${ }^{32}$.

We conclude that the receptors responsible for almost all of the EOG response are located on cilia near to their base, probably on the proximal $40 \mu \mathrm{m}$ of the cilium.

\section{Differences among odorants}

EOG amplitudes increase linearly during weeks 2, 3 and 4 of epithelial regeneration following zinc-induced necrosis (Fig. 2). Receptor neurons are continuously being added to the population during this period and all of these are in that state which we have called immature. During regeneration following axotomy, new axons re-establish contact with the bulb 30 -40 days after surgery in the frog ${ }^{5,16}$, and about 45 days after surgery in the salamander ${ }^{36}$. Thus, in our preparation up to 28 days following zinc treatment, none of the axons have reached the olfactory bulb to make connections with the second order neurons and all have motile cilia. The linear EOG amplitude increase probably reflects the constant expansion rate of the receptor cell population.

A somewhat surprising finding is that the rate of the EOG increase for different odorous substances during regeneration is different. The rate of receptor molecule synthesis and membrane incorporation 
may be different for different receptors, ionophore conductances for different receptors may differ in the immature stage of development or subpopulations of cells specific for particular odors may develop at different rates.

An analysis of variance of the data shows that some inferences can be drawn about the causes of the slope differences in Fig. 2. These are tentative because the number of animals was small.

The plots of Fig. 2 suggest that there are strong effects due to time (since the slopes are not zero) and also to odor (since the slopes are unique). The statistical analysis verified these observations. Odor was significant in the first test. When the odorant parameters were covaried out, time and 4 physical parameters, MOL, MR, MV and LP, were sufficient to account for the observed differences. Odor was not significant. Thus, it is probably simple physical properties of the odorant that account for the observed differences and not an effect of odor that would be related to a specific receptive membrane property.

This contrasts with the results of the same analysis performed on EOG data collected during the first $24 \mathrm{~h}$ after deciliation. Here it was primarily time which accounted for the increase in EOG amplitudes. There is only a tendency toward significance for the effect of the physical parameters. There are two subpopulations of regrowing olfactory cilia, one motile and one immotile. The tendency toward significance may be related to the contribution of EOG currents generated by the motile cilia.

\section{Maturation}

No sharp resistance discontinuity as the electrode traversed the epithelial layer was evident during the first 2 weeks after $\mathrm{ZnSO}_{4}$ treatment; it was seen after this time. In the normal mouse epithelium, the number of intramembranous particles increases greatly when the developing olfactory knob appears above the level of the junctional complex ${ }^{20}$. The reestablishment of normal tissue resistivities, therefore, is probably related to the appearance of the olfactory knobs at about the 13th day after treatment.

It is clear that complex changes in receptor physiology occur at about the half-way point in the cell lifetime, i.e. about 4 weeks. In a minority of the animals, the maturation of the receptor property did not happen on schedule, although in most it did. Our experi- ments do not indicate whether this maturation process involves changes in receptor site specificity, increased synthesis of new receptors, or changes in the properties of the presumed ionophores to which the receptor sites are coupled.

\section{Implications}

Our observations may also account for discrepancies between recorded neural activity and EOG measurements. The summated neural response usually closely reproduces the EOG ${ }^{21}$, but under certain conditions, it can be demonstrated that the EOG behaves differently ${ }^{28}$. This is also true of the slow bulbar potential ${ }^{31}$. Since the EOG sums activity of both mature and immature receptor cells, responises to which immature cells contribute much of the evoked current may account for some of the differences.

Much of what Ottoson reported in his seminal paper of $1956^{30}$, in which he described the EOG recorded in the normal nose, has withstood the test of time. Our conclusions confirm the hypotheses of earlier investigators, who, on the basis of morphological ${ }^{19.34}$, behavioral ${ }^{24}$, and electrophysiological ${ }^{30}$ results speculated that odorant-receptor interaction occurs at the olfactory cilium. We extend these results by showing that the proximal portions of the cilia account for most transduction current. Finally we show that the EOG is more complex than had been expected. It is composed of contributions from two subpopulations of cells with different physiological properties and that for different stimulus substances the two subpopulations contribute differently to the total evoked receptor current. Because axons of one subpopulation have not extended to reach the olfactory bulb, that portion of the EOG contributed by these cells does not measure CNS input.

\section{ACKNOWLEDGEMENTS}

This work was supported by National Science Foundation Grant BNS-8117075 and National Institutes of Health Grants NS14663 and NS18490. We wish to thank Lynn Halpern and Philip Burns for directing and performing the multivariate statistical analysis. 


\section{REFERENCES}

1 Alberts, J. R., Producing and interpreting experimental olfactory deficits, Physiol. Behav., 12 (1974) 657-670.

2 Alberts, J. R. and Galef, B. G., Acute anosmia in the rat: a behavioral test of a peripherally-induced olfactory deficit, Physiol. Behav., 6 (1971) 619-621.

3 Atema, J., Microtubule theory of sensory transduction, $J$. theor. Biol., 39 (1973) 181-190.

4 Bronshtein, A. A., Odor Receptors of Vertebrates, Monograph, Acad. of Sci., Inst. of Comp. Physiol. and Biochem., Leningrad, USSR, 1977, (Chapt. 9 and 10 transl. by B. Menco, Univ, of Utrecht, Holland).

5 Burns, S. M., Mitchell, J. A., Getchell, M. L. and Getchell, T. V., Functional correlates of degeneration and renewal of cilia and knobs of olfactory receptor neurons in the frog, Chem. Sens., 6 (1981) 307-315.

6 Cancalon, P., Effect of salts, $\mathrm{pH}$ and detergents on the catfish olfactory mucosa. In H. van der Starre (Ed.), Olfaction and Taste VII, IRL Press, London, 1980, pp. 73-76.

7 Cancalon, P., Degeneration and regeneration of olfactory cells induced by $\mathrm{ZnSO}_{4}$ and other chemicals, Tissue Cell, 14 (1982) 717-733.

8 Chastrette, M., An approach to a classification of odors using physico-chemical parameters, Chem. Sens., 6 (1981) 157-163.

9 Døving, K. B., Odorant properties correlated with physiological data, Ann. N.Y. Acad. Sci., 247 (1974) 184-192.

10 Gesteland, R. C. and Howland, B., Bridge for measuring the impedance of metal microelectrodes, Rev. Sci. Instr. 50 (1959) 262-264.

11 Gesteland, R. C., Howland, B., Lettvin, J. Y. and Pitts, W. H., Comments on microelectrodes, Proc. I.R.E., 47 (1959) $1856-1862$.

12 Gesteland, R. C., Lettvin, J. Y. and Pitts, W. H., Chemical transmission in the nose of the frog, J. Physiol. (Lond.), 191 (1965) 525-559.

13 Gesteland, R. C., Yancey, R. A. and Farbman, A. I., Development of olfactory receptor neuron selectivity in the rat fetus, Neuroscience, 7 (1982) 3126-3136.

14 Gesteland, R. C., Yancey, R. A., Mair, R. G., Adamek, G. D. and Farbman, A. I., Ontogeny of olfactory receptor specificity. In H. van der Starre (Ed.), Olfaction and Taste VII, IRL Press, London, 1980, pp. 143-146.

15 Getchell, T. V., Heck, G. L., DeSimone, J. A. and Price, $\mathrm{S}$., The location of olfactory receptor sites, inferences from latency measurements, Biophys. J., 30 (1980) 397-411.

16 Graziadei, P. P. C. and DeHan, R. S., Neuronal regeneration in frog olfactory system, $J$. Cell Biol., 59 (1973) 525-530.

17 Graziadei, P. P. C. and Metcalf, J. F., Autoradiographic and ultrastructural observations on the frog's olfactory mucosa, Z. Zellforsch., 116 (1971) 305-318.

18 Harding, J. W., Getchell, T. V. and Margolis, F. L., Denervation of the primary olfactory pathway in mice. $V$. Long term effect of intranasal $\mathrm{ZnSO}_{4}$ irrigation on behavior, biochemistry and morphology, Brain Research, 140 (1978) 271-285.

19 Hopkins, A. E., The olfactory receptors in vertebrates, $J$. comp. Neurol., 41 (1926) 253-289.
20 Kerjaschki, D., Some freeze-etching data on the olfactory epithelium. In J. LeMagnen and P. MacLeod (Eds.), Olfaction and Taste VI, IRL Press, London, 1977, pp. 75-85.

21 Kimura, K., Olfactory nerve response of frog, Kumamoto med. J., 14 (1961) 37-46.

22 Laffort, D., Patte, F. and Etcheto, M., Olfactory coding on the basis of physcochemical properties, Ann. N.Y. Acad. Sci., 247 (1974) 193-208.

23 Mair, R. G., Gesteland, R. C. and Blank, D. L., Changes in olfactory receptor cilia morphology and physiology during development, Neuroscience, 7 (1982) 3091-3103.

24 Matthes, E., Der Einfluss des Mediumwechels auf das Geruchsvermogen von Triton, Z. vergl. Physiol, 5 (1927) 83-166.

25 Matulionis, D. H., Ultrastructure study of mouse olfactory epithelium following destruction by $\mathrm{ZnSO}_{4}$ and its subsequent regeneration, Amer. J. Anat., 142 (1975) 67-90.

26 Moulton, D. G., Dynamics of cell populations in the olfactory epithelium, Ann. N.Y. Acad. Sci., 247 (1974) 52-61.

27 Moulton, D. G., Celebi, G. and Fink, R. P., Olfaction in mammals - two aspects: proliferation of cells in the olfactory epithelium and sensitivity to odours. In G. E. W. Wolstenholme and J. Knight (Eds.), Taste and Smell in Vertebrates, Churchill, London, 1970, pp. 227-246.

28 Mozell, M. M., Olfactory mucosal and neural responses in the frog, Amer. J. Physiol., 213 (1962) 183-196.

29 Mulvaney, B. D. and Heist, G. E., Regeneration of olfactory epithelium, Amer. J. Anat., 131 (1971) 241-252.

30 Ottoson, D., Analysis of the electrical activity of the olfactory epithelium, Acta physiol. scand., Suppl. 36, 122 (1956) $1-83$.

31 Ottoson, D., Comparison of slow potentials evoked in the frog's nasal mucosa and olfactory bulb by natural stimulation, Acta. physiol. scand., 47 (1959) 149-159.

32 Reese, T. S., Olfactory cilia in the frog, J. Cell Biol., 26 (1965) 209-230.

33 Schultz, E. W., Regeneration of olfactory cells, Proc. Soc. Exp. Biol. (N.Y.), 46 (1941) 41-43.

34 Schultze, M. S., Untersuchungen über den Bau der Nasenschleimhaut, Abhandl. Naturforsch. Ges. Halle, 7 (1862) 1-100.

35 Shibuya, T., Dissociation of olfactory neural response and mucosal potentials, Science, 143 (1964) 1338-1340.

36 Simmons, P. A. and Getchell, T. V., Neurogenesis in olfactory epithelium: loss and recovery of transepithelial voltage transients following olfactory nerve section, $J$. Neurophysiol., 43 (3) (1981) 516-528.

37 Smith, C. G., Changes in the olfactory mucosa and the olfactory nerves following intranasal treatment with $\mathrm{ZnSO}_{4}$, Canad. med. Ass. J., 40 (1938) 138-140.

38 Smith, C. G., Regeneration of sensory olfactory epithelium and nerves in adult frogs, Anat. Rec., 109 (1951) 661-671.

39 Takagi, S. F. and Yajima, T., Electrical responses to odours of degenerating olfactory epithelium, Nature (Lond.), 212 (1964) 1220.

40 Takagi, S. F. and Yajima, T., Electrical activity and histological change in the degenerating olfactory epithelium, $J$. gen. Physiol., 48 (1965) 559-569.

41 Tucker, D., Olfactory cilia are not required for receptor function, Fed. Proc., 27 (1967) 544. 